\title{
Transport Properties of Shale Gas in Relation to
}

\section{Kerogen Porosity}

Manolis Vasileiadis ${ }^{1}$, Loukas D. Peristeras ${ }^{1,}$, , Konstantinos D. Papavasileiou ${ }^{1}$, Ioannis G.

$$
\text { Economou }^{1,2, *}
$$

${ }^{1}$ National Center for Scientific Research "Demokritos", Institute of Nanoscience and Nanotechnology, Molecular Thermodynamics and Modelling of Materials Laboratory, GR15310 Aghia Paraskevi Attikis, Greece

${ }^{2}$ Texas A\&M University at Qatar, Chemical Engineering Program, Education City, PO Box 23874, Doha, Qatar

\begin{abstract}
Kerogen is a micro-porous amorphous solid, which consist the major component of the organic matter scattered in the potentially lucrative shale formations hosting shale gas. Deeper understanding of the way kerogen porosity characteristics affect the transport properties of hosted gas is important for the optimal design of the extraction process. In this work, we employ molecular simulation techniques in order to investigate the role of porosity on the adsorption and transport behavior of shale gas in overmature type II kerogen found at many currently productive shales. To account for the wide range of porosity characteristics present in the real system, a large set of 60 kerogen structures that exhibit a diverse set of void space attributes was used. Grand Canonical Monte Carlo (GCMC) simulations were performed for the study of the adsorption of $\mathrm{CH}_{4}, \mathrm{C}_{2} \mathrm{H}_{6}, n-\mathrm{C}_{4} \mathrm{H}_{10}$ and $\mathrm{CO}_{2}$ at $298.15 \mathrm{~K}$ and $398.15 \mathrm{~K}$ and a variety of
\end{abstract}


pressures. The amount adsorbed is found to correlate linearly with the porosity of the kerogen. Furthermore, the adsorption of a quaternary mixture of $\mathrm{CH}_{4}, \mathrm{C}_{2} \mathrm{H}_{6}, \mathrm{CO}_{2}$ and $\mathrm{N}_{2}$ was investigated in the same conditions, indicating that the composition resembling that of the shale gas is achieved under higher temperature and pressure values, i.e. conditions closer to these prevailing in the hosting shale field. The diffusion of $\mathrm{CH}_{4}, \mathrm{C}_{2} \mathrm{H}_{6}$ and $\mathrm{CO}_{2}$, both as pure components and as components of the quaternary mixture, was investigated using equilibrium Molecular Dynamics (MD) simulations at temperatures of 298.15 and $398.15 \mathrm{~K}$ and pressures of 1 and $250 \mathrm{~atm}$. In addition to the effect of temperature and pressure, the importance of limiting pore diameter (LPD), maximum pore diameter (MPD), accessible volume $\left(V_{\text {acc }}\right)$ and accessible surface $\left(S_{\text {acc }}\right)$ on the observed adsorbed amount and diffusion coefficient was revealed by qualitative relationships. The diffusion across the models was found to be anisotropic and the maximum component of the diffusion coefficient to correlate linearly with LPD, indicating that the controlling step of the transport process is the crossing of the limiting pore region. Finally, the transport behavior of the pure compounds was compared with their transport properties when in mixture and it was found that the diffusion coefficient of each compound in the mixture is similar to the corresponding one in pure. This observation agrees with earlier studies in different kerogen models comprising wider pores that have revealed negligible cross-correlation Onsager coefficients.

\section{Introduction}

Unconventional oil and gas refers to oil and gas found in reservoirs of low permeability. As a consequence of this situation, ingenious engineering techniques are necessary for the extraction of unconventional hydrocarbons in an economically and environmentally sustainable way. Two revolutionary techniques that have enabled the commercial exploitation of unconventional reservoirs are: i) the hydraulic fracturing or "fracking" and ii) the extended 
horizontal drilling. Among the various unconventional sources of oil and gas (such as tight gas, oil sands etc.), shale gas (SG) formations have attracted a lot of attention over the past decades. Currently, USA is probably the only major shale gas producer around the world with a remarkably sharp increase of the shale gas produced in the country since 2004 and very optimistic forecast for further increase in the near future. The Barnett shale in $\operatorname{Texas}^{1}$ is the most famous example of successful commercially exploited shale.

SG refers to natural gas (NG) stored in shale formations, i.e. clay minerals that host nodules of organic matter that are capable of generating NG. The gas is primarily located either in adsorbed or dissolved form in the organic matter. Kerogen, the main component of the organic matter, is usually defined as the insoluble -in common organic solvents- part of shales. It is essentially a poly-disperse mixture of macromolecules whose exact chemical composition is unknown and only a few characteristics are determined (e.g. relative number of $\mathrm{H}$ and $\mathrm{C}, \%$ nitrogen, the part of it which is pyrrolic etc.). ${ }^{2}$ For a detailed description of kerogens, the interested reader is referred to the relevant literature such as the review article of Vandenbrouke. ${ }^{3}$

SG is chemically indistinguishable from conventional NG, having all its advantages over other fossil fuels (e.g. coal) such as lower $\mathrm{CO}_{2}, \mathrm{NO}_{\mathrm{x}}$ and sulphur combustion emissions. ${ }^{4}$ When it is compared to other alternative sources of energy (e.g. solar or wind) it can be potentially more viable financially. Other factors that contribute to the importance of SG to modern societies are the suppressed NG prices because of its abundance and the increase of the production of SG. This fact in turn results in benefits for the environment. The decreased NG price has made the replacement of coal with NG possible in heavily polluting industrial activities, such as the electricity production. Lastly, SG producing regions experience important economic and industrial development with multiple benefits to the public, such as 
the creation of new employment positions. A detailed discussion on the topic can be found in the review of Sovacool..$^{5}$

Despite the various benefits that the development of SG industry has, SG has also raised concerns associated with its environmental impact. While downstream processing of SG has similar environmental footprint to conventional $\mathrm{NG}$, a life cycle assessment of its environmental impact revealed that it may have 50\% higher greenhouse gas (GHG) emissions than conventional $\mathrm{NG}$, measured as the fraction of $\mathrm{CH}_{4}$ produced that ends up to the atmosphere, ${ }^{6,7}$ although other studies have shown comparable GHG emissions to conventional NG. ${ }^{8}$ This discrepancy is attributed primarily to the $\mathrm{CH}_{4}$ emitted with flow-back fluids and during the drilling of the wells.$^{6,7}$ The public is also concerned about increased seismic activity in regions neighboring SG extraction wells that may be related to hydraulic fracturing. ${ }^{9}$ Last but not least, the possibility of contamination of water by $\mathrm{CH}_{4}$ or naturally occurring radioactive materials is not considered negligible..$^{10,11}$

While it is recognized that potential environmental hazards should be predicted and prevented as in every industrial activity, this is not the only issue that needs to be addressed. It is well known that every shale is unique, and therefore each one requires its own production design. To make things more complex, the design of a fracturing process may require amendments within the same well because of variation of the geological characteristics. ${ }^{12}$ Finally, the productivity of SG reservoirs decays very fast requiring re-stimulation, and usually the expected ultimate recovery (EUR) of gas does not exceed $50 .{ }^{4,12}$ It is evident that there is substantial room for improvement on SG extraction technology, targeting both its environmental impact and its performance.

Oil and gas industry and academia have devoted significant research efforts over the last years, trying to tackle the problems related to SG exploitation. Common experimental techniques used on shale or kerogen samples include $\gamma$ ray $\log ,{ }^{1,13}$ resistivity measurements, ${ }^{13}$ 
speed of sound, adsorption experiments, ${ }^{14}$ neutron scattering, ${ }^{15}$ X-ray diffraction, vitrinite reflectance, ${ }^{1}$ Rock-Eval pyrolysis etc. ${ }^{16}$ Information acquired by these experiments includes shale field composition in different clays and other minerals, total porosity, pore structure characterization, adsorption isotherms, total organic carbon (TOC), and kerogen density, among others.

Although this broad variety of experimental techniques enables the identification of the most promising shale fields for commercial exploitation, and allows the design of the production processes, it does not provide insight to the underlying molecular and macroscopic phenomena crucial for production that are related to length and time scales inaccessible to experiment. Molecular simulation has proven highly valuable towards this direction for the oil and gas industry. ${ }^{17-19}$ With the boost of SG production in the USA, there is a rapidly growing interest in modelling several complex chemical systems, such as clays and kerogen. The majority of work related to clays focuses on different types of fluids in slit type mineral micro and meso pores. ${ }^{20-24}$ On the other hand, the research effort on kerogens focuses in the creation of realistic kerogen models where the adsorption of fluids of interest to SG technology and their transportation properties can be studied. In the pioneering work of Behar and Vandenbrouke, ${ }^{25}$ realistic 2D models of three types of kerogens at different maturation stages were presented for the first time. Many other attempts employing different computational techniques, from ab initio to classical molecular simulations and strategies for creating realistic kerogen models have followed in the succeeding years. ${ }^{26-31}$ Two methods that have recently gained popularity are the hybrid reverse Monte Carlo (HRMC) simulation method and a class of methods that are based on the assumption that kerogen consists of a single representative molecular model. The HRMC method is a reverse MC method employing a reactive force field aiming to reproduce an experimentally known property, such as the radial distribution function. The methods that are based on representative molecular models assume that kerogen consists of 
well-defined molecules of rather low molecular weight. A number of this representative "kerogen molecules" is placed in a simulation box with or without other lighter compounds. Then, based on a cooling protocol, the system assumes realistic densities.

Models that have been created with the representative molecule approach were used to study adsorption of $\mathrm{CH}_{4},{ }^{29,32} \mathrm{CH}_{4} / \mathrm{C}_{2} \mathrm{H}_{6}$ mixtures, ${ }^{33}{ }^{a} \mathrm{CH}_{4} / \mathrm{C}_{2} \mathrm{H}_{6} / \mathrm{C}_{3} \mathrm{H}_{8}$ ternary mixture and $\mathrm{CO}_{2} .{ }^{32}$ In a very interesting article, Ho et al. ${ }^{34}$ created type II kerogen models based on a previously published "kerogen molecule", representative of currently active shale fields. They studied adsorption of $\mathrm{CH}_{4}$ using GCMC and modelled desorption via equilibrium Molecular Dynamics (MD) simulations using classical force fields. In these latter simulations, $\mathrm{CH}_{4}$ molecules were removed during a MD simulation when they were entering a pre-specified region in structures. In this way, they approached the problems of rapidly decreasing productivity that is commonly observed in shale reservoirs, and the significant amount of $\mathrm{CH}_{4}$ that cannot be extracted from the shales.

Apart from the study of adsorption, the transport properties of several hydrocarbons have been studied, shedding light to many aspects of diffusion in the ultra-confined kerogen environment. Collell et al. ${ }^{31}$ studied the transport properties of light hydrocarbons in twenty models of organic matter dispersed in shales composed of kerogen and other lighter compounds. They proved that diffusion of $\mathrm{CH}_{4}, \mathrm{C}_{2} \mathrm{H}_{6}, \mathrm{C}_{3} \mathrm{H}_{8}, n-\mathrm{C}_{4} \mathrm{H}_{10}, n-\mathrm{C}_{8} \mathrm{H}_{18}$ and $\mathrm{CO}_{2}$ is slowed down in kerogen by comparison to the corresponding diffusion coefficients of the bulk compounds. Then, focusing on one of the twenty models, they further studied the transport properties by means of both equilibrium and non-equilibrium MD. ${ }^{35}$ This study proved that cross-correlation Onsager coefficients are negligible compared to their auto-correlation counterparts, indicating that the diffusion of each compound is not affected by the presence of other compounds. Furthermore, they observed that the diffusion of the light normal hydrocarbons scale as the inverse of their carbon number. Falk et al. ${ }^{36}$ focused on the study of 
$n$-alkanes transport along a single kerogen model constructed by means of a HRMC scheme. Based on their work, they developed the free volume theory of fluid transport in ultra-confined environment. They proved that macroscopic hydrodynamics are not valid in the micropores of kerogen. Then, based on the fluctuation dissipation theorem and observations about the scaling of observed diffusion coefficients with respect to the loading of the structures and the size of the hydrocarbons, they formulated expressions relating the diffusion coefficient and permeance to the free volume accessible to diffusing molecules. The free volume theory of diffusion of pure compounds has also been extended to mixtures. ${ }^{37}$ The extension was based on the observation of negligible correlation of the motion of molecules of different species of the mixture but also negligible correlation between the motions of the molecules of the same species.

The objective of this work is the investigation of qualitative relationships between the porosity of kerogen and the adsorption and diffusion coefficient of light hydrocarbons and shale gas. A large number of pre-constructed kerogen models exhibiting a wide variety of porosity characteristics were used. These models comprise pores spanning the whole spectrum of micropores from diameters of 2 to $23 \AA$. The porosity was studied with a Voronoi based algorithm developed earlier by us. ${ }^{38}$ Here, porosity was characterized based on the limiting pore diameter (LPD), the maximum pore diameter (MPD), the accessible volume $\left(V_{\text {acc }}\right)$ and the accessible surface $\left(S_{\text {acc }}\right)$. The gases that were studied are $\mathrm{CH}_{4}, \mathrm{C}_{2} \mathrm{H}_{6}, n-\mathrm{C}_{4} \mathrm{H}_{10}, \mathrm{CO}_{2}$ and a SG type mixture composed of $\mathrm{CH}_{4}, \mathrm{C}_{2} \mathrm{H}_{6}, \mathrm{CO}_{2}$ and $\mathrm{N}_{2}$. Adsorption and diffusion were studied using GCMC and equilibrium MD simulations respectively. Finally, the observed diffusion coefficient of the mixture components was compared with the diffusion coefficient of the corresponding pure components. 


\section{Molecular simulation methods}

\subsection{Kerogen models}

We studied adsorption and diffusion in bulk kerogen models developed earlier. ${ }^{38}$ These are models of over-mature type II kerogen that were constructed under the assumption that kerogen consists of a single type of molecular units and thus ignoring the true poly-disperse nature of kerogen. The molecular unit used, named II-D, has been published earlier, ${ }^{28}$ and it was constructed based on experimental data from the Duvernay shale. ${ }^{2}$ Apart from these experimental data that we implicitly used, no other prior knowledge was used for the construction of these models. Although this simplification fails to completely describe the complex molecular architecture of real kerogen, it is a necessary simplification in order to render the problem of construction bulk kerogen models feasible. In addition to that, these models have a microporosity that captures the main characteristics of the real material and predict sufficiently accurately properties such as density and porosity. Furthermore, it is anticipated that having the correct porosity would be adequate to study adsorption and diffusion given that the II-D model respects a set of important characteristics of the chemistry of the real material and therefore in the more realistic polydisperse mixtures similar gas-kerogen interactions are expected.

The models that we used for this study consisted of 50 II-D molecules and were constructed based on a staged cooling protocol in which a system of density of $0.01 \mathrm{~g} \mathrm{~cm}^{-3}$ is brought to realistic densities by successive MD simulations at the isothermal-isobaric NPT ensemble that result in equilibration of the system at progressively low temperature ${ }^{38}$. The initial temperature of this cooling protocol was $1100 \mathrm{~K}$ and the final was $298.15 \mathrm{~K}$. In addition to the six structures constructed this way, a number of structures were created with the aid of a number of LennardJones (LJ) dummy particles of varying size. The LJ dummy particle(s) were included in the structure during the staged cooling procedure. Finally, they are removed and kerogen is 
equilibrated with a new MD simulation. The LJ dummy particle(s) were used to control induction of porosity in the model. The number of LJ particles was varied between 1 and 3, while their diameter was varied from $15 \AA$ to $40 \AA$. The force field used for the construction of these models was a general Amber force field (GAFF) ${ }^{39}$ with ab initio (HF/6-31G*) derived atomic point charges. ${ }^{40}$

In the study of adsorption, all the available models comprising 50 II-D molecules were used which is a collection of overall 60 kerogen configurations. The study of transport properties was limited to a subset of these structures that was expected to allow easier diffusion. These are the 24 models that were constructed with 3 × $20 \AA, 1$ x $30 \AA, 2$ x $30 \AA$ and 1 x $40 \AA \mathrm{LJ}$ dummy particle(s) set-ups. In this notation, 2 x $30 \AA$ for example, refers to structures constructed with the aid of two LJ dummy particles each one with $30 \AA$ diameter. In all cases, the configuration of kerogen used was the final configuration of the MD simulations of our previous work. ${ }^{38}$ Since the kerogen structures are of statistical nature, most of their properties present a broad distribution and therefore a kerogen sample cannot be described by a sole configuration but rather an ensemble of characteristic configurations that needs to be used. A detailed characterization of the porosity of these structures is also available in our earlier article. ${ }^{38}$ While none of these models can describe sufficiently kerogen on their own, each one has individual porosity characteristics (e.g. pore size distribution, accessible surface area) that are present in real kerogen, and all together offer a sample for the study of the whole spectrum of micropores (up to $23 \AA$ ) that is known to exist in kerogen.

\subsection{Gases under study}

SG consists of light hydrocarbons, predominantly $\mathrm{CH}_{4}$, and other gases such as $\mathrm{N}_{2}, \mathrm{CO}_{2}, \mathrm{H}_{2} \mathrm{~S}$ etc. As in the case of the conventional NG, the composition of SG varies significantly from reservoir to reservoir, even for different wells of the same reservoir. ${ }^{41}$ In general, the $\mathrm{CH}_{4}$ is the dominant component of SG with composition that varies from $50 \%$ to over $95 \% .{ }^{41,42}$ Given 
the difficulty of direct quantitative comparison of the simulation results with experimental data, as a consequence of the inherent diversity of the real material, a realistic target could only be the acquisition of qualitative information based on molecular modelling. As a result, SG was modelled as a mixture of four components, $\mathrm{CH}_{4}, \mathrm{C}_{2} \mathrm{H}_{6}, \mathrm{CO}_{2}$ and $\mathrm{N}_{2}$, with a molar composition of $85 \%, 7 \%, 4 \%$ and $4 \%$, respectively. In addition, $\mathrm{CH}_{4}, \mathrm{C}_{2} \mathrm{H}_{6}, \mathrm{CO}_{2}$ and $n-\mathrm{C}_{4} \mathrm{H}_{10}$ were studied as pure gases confined in kerogen.

The TraPPE-UA force field ${ }^{43,44}$ was used to model all gases. This force field has been widely used in a variety of applications ${ }^{45-48}$ and it predicts accurately the physical properties of hydrocarbons and $\mathrm{CH}_{4}$, in particular. ${ }^{49,50}$ A rigid united atom model was used for $\mathrm{CH}_{4}$ and $\mathrm{C}_{2} \mathrm{H}_{6}$, while the model for $n-\mathrm{C}_{4} \mathrm{H}_{10}$ comprises two flexible bond angles and a flexible torsion angle. Among the various models for $\mathrm{CO}_{2},{ }^{49}$ we chose to use the TraPPE linear rigid model, in order to ensure compatibility between the models for the other gases. Furthermore, this model is among the most accurate and simple $\mathrm{CO}_{2}$ models. Finally, parameterization of the same force field was used for $\mathrm{N}_{2}$. The cut off distance used for the calculation of van der Waals (vdW) interactions was $14 \AA$, while Coulombic interactions were calculated using the Ewald summation method.

\subsection{Monte Carlo simulation of adsorption}

The GCMC simulation technique was used to study the adsorption of the gases into the complex network of micropores spanning the kerogens. ${ }^{51}$ These simulations were performed using Cassandra, ${ }^{52}$ a general purpose open source Monte Carlo (MC) simulation software. In the GCMC technique, the confined system is under constant temperature and volume and is assumed to be in equilibrium with a reservoir containing the gas under study at certain temperature and pressure conditions. Since the gas under confinement is in equilibrium with the reservoir, the chemical potential of the confined gas is equal to the chemical potential of 
the bulk gas of the reservoir. The chemical potential of the gases were calculated using the following protocol:

i. A system of 500 molecules of the gas was prepared using the Amorphous Builder ${ }^{53}$ utility of the Scienomics MAPS platform. ${ }^{54}$

ii. This system was then fast equilibrated by MD at the isothermal isobaric (NPT) ensemble $^{51}$ using the LAMMPS simulation package. ${ }^{55}$

iii. The equilibrated structure was simulated by MC simulation at the NPT ensemble using Towhee software. ${ }^{56,57}$ During this simulation, the chemical potential was calculated using the Widom test particle insertion method. ${ }^{58}$ Calculations were performed at both 298.15 and $398.15 \mathrm{~K}$ at and pressures up to 250 atm as detailed in Table 1 for each gas studied.

The chemical potential obtained was validated by GCMC simulations at an initially empty box performed using Cassandra software. Finally, GCMC simulations of the gases adsorption in all the selected kerogen models were performed with Cassandra, using the validated values of chemical potential as input.

In all the MD simulations performed in this study an integration time step of $1 \mathrm{fs}$ was used, while pressure and temperature were controlled by a Nosé-Hoover barostat and thermostat, respectively. ${ }^{59,60}$ In all the GCMC simulations, equilibration of the gas was achieved by insertion, deletion, and translation moves for every molecule. For $\mathrm{CO}_{2}$ and $\mathrm{N}_{2}$, rotation about the center of mass was also used, while for $n-\mathrm{C}_{4} \mathrm{H}_{10}$ bond angle bending and torsion rotation moves were used for the equilibration of the internal molecular geometry. The distribution of the number of moves performed in every simulation was uniform. The MC trajectories generated for the pure gases were $2 \times 10^{6}$ steps long, while for SG mixture $4 \times 10^{6}$ steps were performed. 
In all the GCMC simulations, the kerogen matrix was kept rigid. In principle, $\mathrm{MC}$ moves for the equilibration of the conformation of kerogen are necessary for the simultaneous equilibration of the whole system (kerogen and gas). These moves are difficult to implement given the complex structure of the II-D molecule. An alternative for the equilibration of the system is a combined GCMC and MD simulation, where an MD simulation is performed and is paused periodically in order to perform a short GCMC simulation. The gas that was added during the GCMC simulation is then removed before restarting the MD simulation. Here, we performed two test case runs of this type hybrid scheme one at $298.15 \mathrm{~K}$ and 20 atm and one at $398.15 \mathrm{~K}$ and $1 \mathrm{~atm}$ with $\mathrm{CH}_{4}$ being the only exchanged species during the GCMC. It was found that the difference in the adsorbed amount between the two different simulation schemes is smaller than the difference of the adsorbed amount between different kerogen models constructed in a similar manner i.e. same number and size of LJ dummy particles (see Supporting Information, pg. 32). Therefore, the use of a rigid matrix in the GCMC simulation is justified.

\subsection{Study of diffusion of gases in kerogen}

Transport of $\mathrm{CH}_{4}, \mathrm{C}_{2} \mathrm{H}_{6}, \mathrm{CO}_{2}$ and their mixture (SG) along the network of kerogen micropores was studied by equilibrium MD simulations. In all these simulations the assumption of rigid kerogen is relaxed. The pressures considered were $1 \mathrm{~atm}$ and $250 \mathrm{~atm}$ at the temperatures examined in GCMC simulations of adsorption, namely $298.15 \mathrm{~K}$ and 398.15 $\mathrm{K}$. The configuration of each GCMC trajectory whose number of adsorbed molecules of gas was closer to the trajectory average was selected as initial configuration for the diffusion studies. The protocol followed for the estimation of the diffusion coefficient is:

a. A short NPT MD run of 0.5 ns was performed with LAMMPS to relax the system. This is necessary in order to avoid stresses associated with the assumption of rigidly fixed kerogen during the GCMC simulation. 
b. A 0.1 ns NVT MD run, also performed with LAMMPS, with isotropic progressive compression/decompression of the simulation box in order to reach its average size estimated at step (a), brought the system to its equilibrium density.

c. A $60 \mathrm{~ns}$ NVT MD simulation was performed using the GROMACS ${ }^{61-63}$ simulation package for the estimation of the self-diffusion coefficient of the gases in kerogen.

In all the previously mentioned MD simulations, the integration time step was set to $1 \mathrm{fs}$. A Nosé-Hoover thermostat was used to control temperature in all runs and a similar barostat controls pressure in the NPT run of step (a).

The self-diffusion coefficient, $\mathrm{D}_{i, d}^{S}$, of compound $i$ along direction $d=x, y, z$ was calculated using the Einstein relationship ${ }^{51}$ that correlates $\mathrm{D}_{i, d}^{S}$ with the mean squared displacement of the molecules:

$$
\mathrm{D}_{i, d}^{S}=\frac{1}{2 N_{i}} \sum_{j=1}^{N_{i}} \frac{\left\langle\left(r_{i j}^{d}(t+\Delta t)-r_{i j}^{d}(t)\right)^{2}\right\rangle}{\Delta t}
$$

where $r_{i j}^{d}(t)$ is the $d$-component of the position vector of $j^{\text {th }}$ molecule of compound $i$ of the gas, $N_{i}$ is the number of molecules of the $i^{\text {th }}$ compound and the angle brackets indicate an average over all possible displacements $r_{i j}^{d}(t+\Delta t)-r_{i j}^{d}(t)$ along direction $d$ corresponding to time interval $\Delta t$ (i.e. displacements starting from different initial time $t$ ) that can be calculated from the generated MD trajectory. The diffusion coefficient of compound $i$ across the three dimensional space, $\mathrm{D}_{i}^{S}$, was then calculated as an arithmetic average of the three component of the diffusion coefficient, $\mathrm{D}_{i, d}^{s}, d=x, y, z$. The choice of self-diffusion coefficient seems the appropriate choice for the study of transport of SG in kerogen. Earlier studies have revealed negligible cross-correlation Onsager coefficients ${ }^{35,37}$ of mixtures but also 
negligible correlation of the velocities of the molecules of the same species. Therefore all the necessary information about the diffusion of the molecules is indeed included in the selfdiffusion coefficients, $\mathrm{D}_{i, d}^{S}$.

\section{Results and Discussion}

\subsection{Adsorption}

The excess adsorption isotherms at $298.15 \mathrm{~K}$ of $\mathrm{CH}_{4}, \mathrm{C}_{2} \mathrm{H}_{6}, n-\mathrm{C}_{4} \mathrm{H}_{10}$ and $\mathrm{CO}_{2}$ in type II kerogen that was constructed without the use of LJ dummy particles are shown in Figure 1. The excess adsorption, $a^{\mathrm{ex}}$, is defined as the amount of gas adsorbed that exceeds the amount of gas that would fill the pores if the density under confinement was the same as that of the bulk gas. ${ }^{32}$ It is calculated as:

$$
a^{\mathrm{ex}}=a-\rho_{g a s}^{b} \cdot V_{a c c}
$$

where $a$ is the absolute adsorbed amount, and $\rho_{\text {gas }}^{b}$ is the density of the bulk gas as it is calculated during the equilibrium MC run of step (iii) of the algorithm described in section 2.3. $V_{a c c}$ is the volume of kerogen accessible to $\mathrm{CH}_{4}$ that was calculated previously. ${ }^{38}$ The calculated $\rho_{\text {gas }}^{b}$ and $V_{a c c}$ values can be found in the Supporting Information (Tables S3 and S4 respectively). The isotherms presented in Figure 1 were calculated as the average of the six trajectory averages that were generated by GCMC simulations in different kerogen models using a similar construction strategy (i.e. number and size of LJ particle), while the confidence intervals are the corresponding standard deviations.

In general, at the high pressure region the excess adsorbed amount of $\mathrm{CH}_{4}$ is larger than the excess adsorbed amount of $\mathrm{C}_{2} \mathrm{H}_{6}$, while the adsorbed amount of $n-\mathrm{C}_{4} \mathrm{H}_{10}$ is the lowest. This is consistent with the intuitive expectation that at high pressure where the pores are practically 
completely filled, higher amounts of the smaller molecules could be adsorbed. Nevertheless, in all pressures, the amount of the adsorbed $\mathrm{CO}_{2}$ is higher than the rest of the gases examined although is of size larger than $\mathrm{CH}_{4}$. This is an indication of noticeably stronger interactions of $\mathrm{CO}_{2}$ with kerogen compared to the hydrocarbons. Saturation of $n-\mathrm{C}_{4} \mathrm{H}_{10}$ is practically immediately achieved at very low pressure, while the system is saturated in $\mathrm{C}_{2} \mathrm{H}_{6}$ at much lower pressure compared to $\mathrm{CH}_{4}$. As it is shown in Figure $1 \mathrm{~b}$, even at a pressure as low as $0.1 \mathrm{~atm}$, the system is already saturated with $n-\mathrm{C}_{4} \mathrm{H}_{10}$. The average statistical uncertainty with respect to the calculated average $a^{\text {ex }}$ value is $8 \%$ for $\mathrm{CH}_{4}$ with values not exceeding $15 \%, 10 \%$ for $\mathrm{C}_{2} \mathrm{H}_{6}$ with maximum value of $18 \%, 12 \%$ for $n-\mathrm{C}_{4} \mathrm{H}_{10}$ with maximum value of $23 \%$ and finally $9 \%$ for $\mathrm{CO}_{2}$ with uncertainty not exceeding $16 \%$. The adsorption isotherms on the other kerogen models constructed with the aid of LJ particles (as shown in the Supporting Information Figures S1-S8) have similar qualitative characteristics.

Figure 2 shows the excess adsorption, $a^{\mathrm{ex}}$, isotherms of the pure $\mathrm{CH}_{4}, \mathrm{C}_{2} \mathrm{H}_{6}, \mathrm{C}_{4} \mathrm{H}_{10}$ and $\mathrm{CO}_{2}$ at $398.15 \mathrm{~K}$. Comparing to Figure 1 , it is evident that the amount of $n-\mathrm{C}_{4} \mathrm{H}_{10}$ adsorbed is not significantly affected by the increase in temperature remaining around $1 \mathrm{mmol} \mathrm{g}^{-1}$ for any pressure. On the other hand, a similar comparison of Figures 1 and 2 reveals that the excess adsorbed amount of $\mathrm{CH}_{4}, \mathrm{C}_{2} \mathrm{H}_{6}$, and $\mathrm{CO}_{2}$ decreases at each pressure with increasing temperature. The higher decrease is observed at the lowest pressure and the lower decrease observed for the higher pressure. More specifically, the $\%$ relative decrease $\frac{a^{\mathrm{ex}}(298.15 \mathrm{~K})-a^{\mathrm{ex}}(398.15 \mathrm{~K})}{a^{\mathrm{ex}}(298.15 \mathrm{~K})}$ is approximately $80 \%$ at 1 atm and $20 \%$ at 250 atm for $\mathrm{CH}_{4}, 60 \%$ at 1 atm and $5 \%$ at 250 atm for $\mathrm{C}_{2} \mathrm{H}_{6}$, and $75 \%$ at $1 \mathrm{~atm}$ and $5 \%$ at $250 \mathrm{~atm}$ for $\mathrm{CO}_{2}$. At 398.15 $\mathrm{K}$, saturation is achieved at higher pressures for $\mathrm{CH}_{4}, \mathrm{C}_{2} \mathrm{H}_{6}$, and $\mathrm{CO}_{2}$ with excess adsorption isotherms that have not reached their maximum. Finally, one can observe the wider range of pressures that the isotherm of $\mathrm{C}_{2} \mathrm{H}_{6}$ remains above the isotherm of $\mathrm{CH}_{4}$. 
The effect of the LJ dummy particles on adsorption (more and larger LJ dummy particles increases the porosity of kerogen) can be identified from Figure 3 where the loading, $a$, is presented as function of the $\%$ porosity of the kerogen calculated as:

$$
\% \text { porosity }=\frac{V_{a c c}}{V} \cdot 100
$$

where $V$ is the volume of kerogen which is equal to the cubic simulation box and $V_{\text {acc }}$ the $\mathrm{CH}_{4}$ accessible volume. The amount of adsorbed gas is a linear (increasing in all cases apart from the case of $1 \mathrm{~atm}$ for $\mathrm{CH}_{4}$ and $\mathrm{CO}_{2}$ ) function of the accessible volume. This linear trend of the adsorption with respect to porosity is observed at both high and low pressures. The increase of pressure increases the slope of the linear trend line for $\mathrm{CH}_{4}, \mathrm{C}_{2} \mathrm{H}_{6}$, and $\mathrm{CO}_{2}$. For $n-\mathrm{C}_{4} \mathrm{H}_{10}$, there is no significant pressure dependence of the data, since kerogen saturation is observed at low pressures (Figure 1). Therefore, only a single pressure (1 atm) is depicted in Figure 3. It should be pointed out that for $\mathrm{CH}_{4}$ and $\mathrm{CO}_{2}$ at $1 \mathrm{~atm}$, the dependence of adsorbed amount on accessible volume is negligible (the differences between the observed loadings are comparable to the uncertainties of their values) but slightly negative, which may be explained by partial coverage of the surface of the pores by the gas molecules. Another contributing reason for this might be a reduction of the gas/wall interactions at wider pores. ${ }^{65}$

Adsorption of the SG mixture at four sets of temperature and pressure conditions reveals that confinement has a considerable effect on mixture composition, $x_{i}^{\mathrm{c}}$, with $i=$ $\mathrm{CH}_{4}, \mathrm{C}_{2} \mathrm{H}_{6}, \mathrm{CO}_{2}, \mathrm{~N}_{2}$, which strongly deviates from the bulk mixture composition that it is in equilibrium with. This deviation is quantified via the following expression: 


$$
\Delta(P, T)=\sqrt{\left\langle\left(\left\langle\sum_{i \in \mathrm{C}} \frac{x_{i}^{\mathrm{c}}}{x_{i}^{\mathrm{b}}}\right\rangle_{\# \text { run }}-1\right)^{2}\right\rangle_{\mathrm{LJP}}}
$$

In equation (4), the set $\mathrm{C}=\left\{\mathrm{CH}_{4}, \mathrm{C}_{2} \mathrm{H}_{6}, \mathrm{CO}_{2}, \mathrm{~N}_{2}\right\}$ is the set of the compounds composing SG. The ensemble average composition of gas $i$ along the trajectory of the GCMC adsorption simulation in kerogen and along the NPT MC simulation trajectory used for the calculation of the chemical potential, is denoted as $x_{i}^{\mathrm{c}}$ and $x_{i}^{\mathrm{b}}$, respectively. The bracket \langle\rangle$_{\# \text { run }}$ represents an average over the six runs (i.e. kerogen models) constructed with a similar LJ dummy particle(s) set up and the bracket \langle\rangle$_{\mathrm{LJP}}$ an average over the different LJ set ups considered here. The mole fractions, $x_{i}^{\mathrm{b}}$, of the bulk system is $0.85,0.07,0.04$, and 0.04 for $\mathrm{CH}_{4}, \mathrm{C}_{2} \mathrm{H}_{6}$, $\mathrm{CO}_{2}$, and $\mathrm{N}_{2}$, respectively, and independent of pressure and temperature. On the other hand, $x_{i}^{\mathrm{c}}$ was found to vary significantly as a function of pressure and temperature for every kerogen structure. In addition to this, the composition of the confined systems is considerably different for different structures of kerogen. As a consequence of this behavior, $\Delta=\Delta(P, T)$ is a function of the pressure and temperature conditions. It should also be noted that if the composition at certain conditions under confinement is the same as the bulk composition, $\Delta$ approaches zero. Figure 4 shows $\Delta$ for the various temperatures and pressures examined. Increasing the temperature and pressure leads to a composition under confinement which is closer on average (over the various examined structures) to the initially set bulk composition based on which the chemical potential (used for the GCMC adsorption simulations) was calculated. The effect of pressure on the composition under confinement is intuitively understood by the fact that the environment around a molecule under confinement (small distances with the other molecules) resembles more the environment around a molecule of the bulk under high pressure.

\subsection{Diffusion}


Although kerogen is an amorphous material and therefore exhibits isotropic behavior, the diffusion of the gases in the length scale of our models is not isotropic. Due to their limited size, these models may include percolated pores, which allow diffusion along only one direction in the vast majority of the cases examined. In general, $\mathrm{CH}_{4}$ moves faster than $\mathrm{C}_{2} \mathrm{H}_{6}$ and $\mathrm{CO}_{2}$, while $\mathrm{C}_{2} \mathrm{H}_{6}$ diffuses slightly faster than $\mathrm{CO}_{2}$. This ordering of the diffusion coefficients of the hydrocarbons is consistent with the intuitively expected trend, because of the relative size of the molecules. A comparison of the diffusion coefficients of $\mathrm{CH}_{4}$ and $\mathrm{C}_{2} \mathrm{H}_{6}$, $\mathrm{D}_{\mathrm{CH}_{4}}^{S}$ and $\mathrm{D}_{\mathrm{C}_{2} \mathrm{H}_{6}}^{S}$, respectively, at $298.15 \mathrm{~K}$ and 1 atm is shown in Figure 5 . The data are distributed around the straight line with slope $\frac{1}{2}$ in agreement with the earlier published correlations ${ }^{35}$ stating that $\mathrm{D}_{\mathrm{C}_{2} \mathrm{H}_{6}}^{S} \approx \frac{\mathrm{D}_{\mathrm{CH}}}{2}$. The slope of the trend line fitted to the data is 0.4865 very close to the theoretically expected value of 0.5 .

In an effort to study the characteristics of porosity that affect the mobility of gases inside the kerogen, the relationship between the diffusion coefficients and the porosity was examined. Figure 6 shows the maximum component of the diffusion coefficient:

$$
D_{i}^{S}=\max _{d \in\{x, y, z\}} \mathrm{D}_{i, d}^{S}
$$

of the three pure gases studied at $298.15 \mathrm{~K}$ and $250 \mathrm{~atm}$ as function of the kerogen limiting and maximum pore diameter (LPD and MPD, respectively) for the 24 different kerogen structures considered. The limiting and maximum pore diameters were calculated as average of their instantaneous values for 11 configurations evenly selected along 1 ns of the of the NVT run of step (c) of the algorithm described in the subsection 2.4. The instantaneous values of the porosity characteristics of interest on each one of the 11 selected configuration of each MD run were calculated using a Voronoi tessellation based algorithm that we developed previously. ${ }^{38}$ 
It should be stressed out that pores are examined free of any diffusing gas so that the calculations are free of non-kerogen atoms. Therefore, during the calculation of the porosity characteristics the gas that was diffusing along kerogen was removed. The calculation of average LPD was limited to $1 \mathrm{~ns}$ of the NVT simulation, instead of the entire $60 \mathrm{~ns}$ run, in order to reduce the CPU cost that would otherwise render the calculation infeasible.

Here, the focus is on the maximum component of the diffusion coefficient because of the anisotropic character of diffusion along our kerogen molecules, which takes place along one percolated direction. It is reasonable to expect that the maximum component of the diffusion is the one that describes the movement of the gases along this percolated direction. There is a strong, almost linear, correlation between the maximum component of diffusion coefficient and the limiting pore diameter, with increasing values as limiting pore diameter increases. The increased mobility of $\mathrm{CH}_{4}$ compared to $\mathrm{C}_{2} \mathrm{H}_{6}$ and $\mathrm{CO}_{2}$ is indicated by the higher slope of the trend line shown in Figure 6a, compared to the slope in Figure $6 \mathrm{~b}$ and $6 \mathrm{c}$. No correlation at all is observed between the maximum component of diffusion coefficient and the observed MPD, for all pure compounds.

It is worth noting that a measurable diffusion coefficient is observed for structures whose LPD is much lower than the molecular diameter of the diffusion gases. This behavior is observed for all compounds, and suggests the existence of a gate opening mechanism that is capable to allow the movement of the gases. The dynamics of this mechanism should be faster than $1 \mathrm{ps}$, which is the time interval between the configurations selected for the study of porosity.

Figure 7 shows the same diffusion coefficient components as a function of the $\mathrm{CH}_{4}$ accessible volume and surface ( $V_{\text {acc }}$ and $S_{\text {acc }}$, respectively). The $V_{\text {acc }}$ and $S_{\text {acc }}$ were calculated with a methodology similar to the methodology followed for the calculation of LPD and MPD of Figure 6. The maximum component of diffusion coefficient, $D_{i}^{S}$, is less correlated to the 
accessible volume and surface compared to its correlation to LPD. Although there is no specific functional form of such a trend, a non-specific increase of the diffusion with increasing volume and surface is observed. For the case of the diffusion coefficient as a function of the accessible surface, there is a dependence on $S_{\text {acc }}$ up to approximately $12,000 \AA^{2}$ while at higher values it disappears.

The relative correlation of the various relationships of the maximum component of the diffusion coefficient with porosity characteristics is quantified with the linear (Pearson's) correlation coefficient:

$$
R=\frac{n \sum\left(x_{i} y_{i}\right)-\sum x_{i} \sum y_{i}}{\sqrt{n \sum x_{i}^{2}-\left(\sum x_{i}\right)^{2}} \sqrt{n \sum y_{i}^{2}-\left(\sum y_{i}\right)^{2}}}
$$

where $x_{i}$ represents the first set of data which in this case are the calculated $D_{i}^{S}, y_{i}$ represents the sets of corresponding porosity data (LPD, MPD, $V_{\text {acc }}$ and $S_{\text {acc }}$ ) and $n$ is the number of collected data points. When the two sets of data are linearly correlated $R$ takes the value of 1 , while no correlation is indicated by a value of 0 . Table 2 shows the correlation coefficients for the four pressure and temperature conditions examined. It is clear that in every case, the correlation coefficient between diffusion coefficient and MPD is the smallest, while correlation between LPD and diffusion is in general strong and in every case stronger than the correlation with the other porosity characteristics. The correlation between diffusion, accessible volume and accessible surface seems similar and generally looser than the correlation with LPD. As indicated by the correlation coefficients of Table 2 , the relationship of $D_{i}^{S}$ and porosity at $398.15 \mathrm{~K}$ is expected to have qualitative behavior similar to corresponding functions at 298.15 K shown in Figures 6 and 7. Figures showing the $D_{i}^{S}$ as function of LPD, MPD, $V_{\text {acc }}$ and $S_{\text {acc }}$ at the other conditions examined, namely $298.16 \mathrm{~K} / 1 \mathrm{~atm}, 398.15 \mathrm{~K} / 1 \mathrm{~atm}$ and $398.15 \mathrm{~K} / 250 \mathrm{~atm}$, 
for the all the studied gases are shown in the Supporting Information (Figures S9-S38). As a general remark, increase of the temperature from $298.15 \mathrm{~K}$ to $398.15 \mathrm{~K}$ for a given pressure results in an increase of the diffusion coefficient for every compound up to a factor of two.

Diffusion of the gas mixture in kerogen was examined using NVT MD simulation data. The amount of $\mathrm{N}_{2}$ was not sufficient to allow meaningful statistical analysis and it was omitted. Figure 8 shows the three diffusion coefficient components (along $\mathrm{x}, \mathrm{y}$ and $\mathrm{z}$ direction) of each of the three remaining compounds (i.e. $\mathrm{CH}_{4}, \mathrm{C}_{2} \mathrm{H}_{6}$ and $\mathrm{CO}_{2}$ ) as a function of the corresponding diffusion coefficient components in pure at $298.15 \mathrm{~K}$ and $250 \mathrm{~atm}$. Data points are positioned around the $\mathrm{x}=\mathrm{y}$ line indicating practically that the diffusion coefficient of every gas remains unchanged between pure and mixture conditions. This finding agrees with earlier studies that have revealed that the motions of the molecules in the confined environment of the pores of kerogen are not correlated. ${ }^{35,37}$ Given that all the components of the self-diffusion coefficient of a compound are essentially unaffected by the presence of the molecules of different compounds, it is reasonable to assume that in general the diffusion mechanism remains the same in the mixture as in the pure state. This behavior does not appear to change with temperature as an equivalent behavior is also observed at $398.15 \mathrm{~K}$ (see Supporting Information Figures S30-S41), although the points are slightly more scattered around the $\mathrm{y}=\mathrm{x}$ line. Note that at $398.15 \mathrm{~K}$, the composition of the SG mixture examined differs from its composition at 298.15 K (Figure 4). Furthermore, the composition of the mixture is different in different kerogen models even at the same temperature. Therefore, it seems that the equivalence between the diffusion mechanisms of either pure compounds or their mixture counterparts is not affected by the composition or temperature.

In addition to the fact that $\mathrm{D}_{i, d}^{S}, d \in\{\mathrm{x}, \mathrm{y}, \mathrm{z}\}$ of each mixture component $i$ is practically the same as the corresponding pure component $\mathrm{D}_{i, d}^{S}$, it should be pointed out that the composition of the diffusing gas has only a minor effect on the characteristics of the porosity of kerogen 
(LPD, MPD, $V_{\text {acc }}$ and $S_{\text {acc }}$ ). As a result, relationships between diffusion coefficients of the three primary components of the SG mixtures and the characteristics of porosity are expected to exist and be similar to the correlations shown in Figure 6 and Figure 7. Indeed, this is true and a similar behavior between the maximum component of diffusion coefficient as function of LPD, MPD, $V_{\text {acc }}$ and $S_{\text {acc }}$ is observed (see Supporting Information). This relationship between diffusion coefficients of the mixture and porosity is also indicated by the correlation coefficients of Table 2.

\section{Conclusion}

The adsorption and transport properties of a SG type mixture along over mature type II kerogen were investigated. A large number of kerogen structures that were constructed and extensively characterized in terms of their porosity in an earlier work were used. These bulk kerogen models were constructed under the assumption that kerogen consists of a single species of relatively small molecules. The porosity was imposed to these kerogen models and effectively controlled with the aid of LJ dummy particles. In this way, the set of kerogen structures used for the study of adsorption and transport properties comprise pores that exhibit a large variety of characteristics and span the whole spectrum of micropores.

Adsorption of three hydrocarbons $\left(\mathrm{CH}_{4}, \mathrm{C}_{2} \mathrm{H}_{6}\right.$ and $\left.n-\mathrm{C}_{4} \mathrm{H}_{10}\right)$ and $\mathrm{CO}_{2}$ was studied using GCMC at various temperature and pressure conditions, assuming that kerogen structure is not affected by the presence of gases in its pores. It was found that at high pressures more $\mathrm{CO}_{2}$ is adsorbed, followed by $\mathrm{CH}_{4}, \mathrm{C}_{2} \mathrm{H}_{6}$ and $n-\mathrm{C}_{4} \mathrm{H}_{10}$ for both temperatures $(298.15 \mathrm{~K}$ and $398.15 \mathrm{~K})$ where isotherms were generated. For the three hydrocarbons, this ordering is consistent with the relative size of the molecules. The fact that more $\mathrm{CO}_{2}$ is adsorbed was attributed to stronger kerogen $/ \mathrm{CO}_{2}$ interactions. Temperature affects both the saturation pressure and the adsorbed amount at each pressure for all gases except $n-\mathrm{C}_{4} \mathrm{H}_{10}$. In general, saturation is achieved at higher 
pressure with increasing temperature, while a smaller amount is adsorbed at every pressure at higher temperature. Finally, with regard to the dependence of adsorption to porosity, a linear relationship is found between the adsorbed gas amount and the $\mathrm{CH}_{4}$ accessible volume with the slope of the line increasing with increasing pressure.

Furthermore, the adsorption of a $\mathrm{SG}$ type mixture composed of $\mathrm{CH}_{4}, \mathrm{C}_{2} \mathrm{H}_{6}, \mathrm{CO}_{2}$ and $\mathrm{N}_{2}$ was studied. It was found that the composition of the adsorbed mixture is significantly different than the bulk gas mixture composition, a difference which was quantified by the quantity $\Delta(P, T)$. Increase of pressure and temperature resulted in a composition closer to the bulk gas composition. $\mathrm{N}_{2}$ amount in the adsorbed confined phase was negligible.

The diffusion of pure $\mathrm{CH}_{4}, \mathrm{C}_{2} \mathrm{H}_{6}$ and $\mathrm{CO}_{2}$ in kerogen was studied at four sets of temperature and pressure conditions, namely $298.15 \mathrm{~K} / 1 \mathrm{~atm}, 298.15 \mathrm{~K} / 250 \mathrm{~atm}, 398.15 \mathrm{~K} / 1 \mathrm{~atm}$ and $398.15 \mathrm{~K} / 250 \mathrm{~atm}$ using equilibrium MD simulation. Diffusion of the same compounds as parts of a quaternary mixture with the addition of $\mathrm{N}_{2}$ was also investigated for both temperatures of $298.15 \mathrm{~K}$ and $398.15 \mathrm{~K}$ but only at high pressure of $250 \mathrm{~atm}$. The qualitative dependence of the observed diffusion coefficient to the LDP, MDP, $V_{\text {acc }}$ and $S_{\text {acc }}$ of kerogen porosity was investigated. The porosity characteristics were calculated along the NVT runs that were used for the study of diffusion. In general, $\mathrm{CH}_{4}$, which is the smallest molecule, diffuses faster than $\mathrm{C}_{2} \mathrm{H}_{6}$ and $\mathrm{CO}_{2}$ with the diffusion coefficient of $\mathrm{CO}_{2}$ being slightly smaller than the diffusion coefficient of $\mathrm{C}_{2} \mathrm{H}_{6}$. The diffusion coefficient of $\mathrm{C}_{2} \mathrm{H}_{6}$ was approximately half the diffusion coefficient of $\mathrm{CH}_{4}$ for every kerogen structure in agreement with previously published correlations. Increase of temperature results in faster diffusion. The maximum component of the self-diffusion coefficient was found to be linearly correlated with the LPD of the structures. The accessible volume and accessible surface were found to be less correlated to diffusion. The diffusion coefficient of each component in the SG type mixture is practically the same with the corresponding pure component diffusion coefficient. This manifests that the 
diffusion of each compound remains unaltered by the presence of the molecules of other compounds. This observation is true for both temperatures examined. Given that the composition of the mixture under confinement is different for different kerogen structures and varies also as a function of temperature, this suggests that the diffusion mechanism stays unaltered in the mixture regardless of its composition. As a result, it may be sufficient when studying SG transport to focus on the pure components alone.

\section{AUTHOR INFORMATION}

\section{Corresponding Authors}

*Emails: i.economou@inn.demokritos.gr, 1.peristeras@inn.demokritos.gr.

\section{Author Contributions}

The manuscript was written through contributions of all authors. All authors have given approval to the final version of the manuscript.

\section{Funding Sources}

All the results reported here were performed under ShaleXenvironmenT, H2020 project, funded by the European Commission Horizon 2020 Framework Programme for Research and Innovation (Grant Agreement no 640979).

\section{Acknowledgment}

We are grateful to European Commission for funding the ShaleXenvironmenT project under Horizon 2020 Programme for Research and Innovation (Grant Agreement no 640979) and to Professor Andrey G. Kalinichev and Professor Martin Lísal for fruitful discussions on modelling kerogens. Computational time was granted from the Greek Research \& Technology Network (GRNET) in the National High Performance Computing facility - ARIS - under 
projects IDs 002043 and 004035 . We are also thankful to the High Performance Computing Center of Texas A\&M University at Qatar for generous resource allocation. Scienomics SARL is acknowledged for providing MAPS software used to generate initial structures of the systems simulated.

\section{ASSOCIATED CONTENT}

\section{Supporting information}

Calculated densities, chemical potentials, accessible volume of the kerogen structures, ideal adsorbed amount of gas in each kerogen model, comparison of the GCMC and hybrid $\mathrm{GCMC} / \mathrm{MC}$ calculations, excess adsorption isotherms of pure gases in the remaining kerogen structures, maximum component of diffusion coefficient as function of the porosity characteristics and comparison of diffusion coefficient of pure components to corresponding mixture components at $398.15 \mathrm{~K}$. 


\section{References}

(1) Montgomery, S. L.; Jarvie, D. M.; Bowker, K. A.; Pollastro, R. M. Mississippian Barnett Shale, Fort Worth Basin, North-Central Texas: Gas-Shale Play with Multi-trillion Cubic Foot Potential. AAPG Bull. 2005, 89, 155-175.

(2) Kelemen, S. R.; Afeworki, M.; Gorbaty, M. L.; Sansone, M.; Kwiatek, P. J.; Walters,

C. C.; Freund, H.; Siskin, M.; Bence, A. E.; Curry, D. J.; et al. Direct Characterization of Kerogen by X-Ray and Solid-State 13 C Nuclear Magnetic Resonance Methods. Energy Fuels 2007, 21, 1548-1561.

(3) Vandenbroucke, M. Kerogen: From Types to Models of Chemical Structure. Oil Gas Sci. Technol. - Rev IFP 2003, 58, 243-269.

(4) King, G. E. Hydraulic Fracturing 101: What Every Representative, Environmentalist, Regulator, Reporter, Investor, University Researcher, Neighbor, and Engineer Should Know About Hydraulic Fracturing Risk. J. Pet. Technol. 2012, 64, 34-42.

(5) Sovacool, B. K. Cornucopia or Curse? Reviewing the Costs and Benefits of Shale Gas Hydraulic Fracturing (Fracking). Renew. Sustain. Energy Rev. 2014, 37, 249-264.

(6) Howarth, R. Methane Emissions and Climatic Warming Risk from Hydraulic Fracturing and Shale Gas Development: Implications for Policy. Energy Emiss. Control Technol. 2015, 3, 45-54.

(7) Howarth, R. W.; Santoro, R.; Ingraffea, A. Methane and the Greenhouse-Gas Footprint of Natural Gas from Shale Formations: A Letter. Clim. Change 2011, 106, 679-690.

(8) Weber, C. L.; Clavin, C. Life Cycle Carbon Footprint of Shale Gas: Review of Evidence and Implications. Environ. Sci. Technol. 2012, 46, 5688-5695. 
(9) Frohlich, C.; Brunt, M. Two-Year Survey of Earthquakes and Injection/Production Wells in the Eagle Ford Shale, Texas, prior to the MW4.8 20 October 2011 Earthquake. Earth Planet. Sci. Lett. 2013, 379, 56-63.

(10) King, G. E.; Durham, D. Environmental Aspects of Hydraulic Fracturing: What Are the Facts? In ACS Symposium Series; Drogos, D. L., Ed.; American Chemical Society: Washington, DC, 2015; Vol. 1216, pp 1-44.

(11) Osborn, S. G.; Vengosh, A.; Warner, N. R.; Jackson, R. B. Methane Contamination of Drinking Water Accompanying Gas-Well Drilling and Hydraulic Fracturing. Proc. Natl. Acad. Sci. 2011, 108, 8172-8176.

(12) Denney, D. Thirty Years of Gas-Shale Fracturing: What Have We Learned? J. Pet. Technol. 2010, 62, 88-90.

(13) Alexander, T.; Baihly, J.; Boyer, C.; Clark, B.; Waters, G.; Jochen, V.; Le Calvez, J.; Lewis, R.; Miller, C. K.; Thaeler, J.; et al. Shale Gas Revolution. Oilfield Rev. 2011, 23, 4055.

(14) Rexer, T. F.; Mathia, E. J.; Aplin, A. C.; Thomas, K. M. High-Pressure Methane Adsorption and Characterization of Pores in Posidonia Shales and Isolated Kerogens. Energy Fuels 2014, 28, 2886-2901.

(15) Clarkson, C. R.; Solano, N.; Bustin, R. M.; Bustin, A. M. M.; Chalmers, G. R. L.; He, L.; Melnichenko, Y. B.; Radliński, A. P.; Blach, T. P. Pore Structure Characterization of North American Shale Gas Reservoirs Using USANS/SANS, Gas Adsorption, and Mercury Intrusion. Fuel 2013, 103, 606-616. 
(16) Okiongbo, K. S.; Aplin, A. C.; Larter, S. R. Changes in Type II Kerogen Density as a Function of Maturity: Evidence from the Kimmeridge Clay Formation. Energy Fuels 2005, 19, 2495-2499.

(17) Papavasileiou, K. D.; Vasileiadis, M.; Michalis, V. K.; Peristeras, L. D.; Economou, I. G. Multi-Scale Models for the Prediction of Microscopic Structure and Physical Properties of Chemical Systems Related to Natural Gas Technology. In Natural gas processing from midstream to downstream.

(18) Rezlerová, E.; Zukal, A.; Čejka, J.; Siperstein, F. R.; Brennan, J. K.; Lísal, M. Adsorption and Diffusion of $\mathrm{C}_{1}$ to $\mathrm{C}_{4}$ Alkanes in Dual-Porosity Zeolites by Molecular Simulations. Langmuir 2017, 33, 11126-11137.

(19) Michalis, V. K.; Costandy, J.; Tsimpanogiannis, I. N.; Stubos, A. K.; Economou, I. G. Prediction of the Phase Equilibria of Methane Hydrates Using the Direct Phase Coexistence Methodology. J. Chem. Phys. 2015, 142, 044501.

(20) Loganathan, N.; Yazaydin, A. O.; Bowers, G. M.; Kalinichev, A. G.; Kirkpatrick, R. J. Molecular Dynamics Study of $\mathrm{CO}_{2}$ and $\mathrm{H}_{2} \mathrm{O}$ Intercalation in Smectite Clays: Effect of Temperature and Pressure on Interlayer Structure and Dynamics in Hectorite. J. Phys. Chem. C 2017, 121, 24527-24540.

(21) Phan, A.; Cole, D. R.; Weiß, R. G.; Dzubiella, J.; Striolo, A. Confined Water Determines Transport Properties of Guest Molecules in Narrow Pores. ACS Nano 2016, 10, $7646-7656$.

(22) Shroll, R. M.; Smith, D. E. Molecular Dynamics Simulations in the Grand Canonical Ensemble: Application to Clay Mineral Swelling. J. Chem. Phys. 1999, 111, 9025-9033. 
(23) Liu, X.; Wang, L.; Zheng, Z.; Kang, M.; Li, C.; Liu, C. Molecular Dynamics Simulation of the Diffusion of Uranium Species in Clay Pores. J. Hazard. Mater. 2013, 244-245, 21-28.

(24) Szczerba, M.; Kuligiewicz, A.; Derkowski, A.; Gionis, V.; Chryssikos, G.; Kalinichev, A. Structure and Dynamics of Water-Smectite Interfaces: Hydrogen Bonding and the Origin of the Sharp O-D w /O-H w Infrared Band From Molecular Simulations. Clays Clay Miner. 2016, 64, 452-471.

(25) Behar, F.; Vandenbroucke, M. Chemical Modelling of Kerogens. Org. Geochem. 1987, $11,15-24$.

(26) Siskin, M.; Scouten, C. G.; Rose, K. D.; Aczel, T.; Colgrove, S. G.; Pabst, R. E. Detailed Structural Characterization of the Organic Material in Rundle Ramsay Crossing and Green River Oil Shales, 143-158. In Snape C. (eds.) Composition, Geochemistry and Conversion of Oil Shales, NATO ASI Series (Series C: Mathematical and physical sciences), vol. 455, Springer, Dordrecht, Netherlands, 1995

(27) Orendt, A. M.; Pimienta, I. S. O.; Badu, S. R.; Solum, M. S.; Pugmire, R. J.; Facelli, J. C.; Locke, D. R.; Chapman, K. W.; Chupas, P. J.; Winans, R. E. Three-Dimensional Structure of the Siskin Green River Oil Shale Kerogen Model: A Comparison between Calculated and Observed Properties. Energy Fuels 2013, 27, 702-710.

(28) Ungerer, P.; Collell, J.; Yiannourakou, M. Molecular Modeling of the Volumetric and Thermodynamic Properties of Kerogen: Influence of Organic Type and Maturity. Energy Fuels 2015, 29, 91-105.

(29) Yiannourakou, M.; Ungerer, P.; Leblanc, B.; Rozanska, X.; Saxe, P.; Vidal-Gilbert, S.; Gouth, F.; Montel, F. Molecular Simulation of Adsorption in Microporous Materials. Oil Gas Sci. Technol. - Rev. D’IFP Energ. Nouv. 2013, 68, 977-994. 
(30) Bousige, C.; Ghimbeu, C. M.; Vix-Guterl, C.; Pomerantz, A. E.; Suleimenova, A.; Vaughan, G.; Garbarino, G.; Feygenson, M.; Wildgruber, C.; Ulm, F.-J.; et al. Realistic Molecular Model of Kerogen's Nanostructure. Nat. Mater. 2016, 15, 576-582.

(31) Collell, J.; Ungerer, P.; Galliero, G.; Yiannourakou, M.; Montel, F.; Pujol, M. Molecular Simulation of Bulk Organic Matter in Type II Shales in the Middle of the Oil Formation Window. Energy Fuels 2014, 28, 7457-7466.

(32) Michalec, L.; Lísal, M. Molecular Simulation of Shale Gas Adsorption onto Overmature Type II Model Kerogen with Control Microporosity. Mol. Phys. 2017, 115, 10861103.

(33) Collell, J.; Galliero, G.; Gouth, F.; Montel, F.; Pujol, M.; Ungerer, P.; Yiannourakou, M. Molecular Simulation and Modelisation of Methane/Ethane Mixtures Adsorption onto a Microporous Molecular Model of Kerogen under Typical Reservoir Conditions. Microporous Mesoporous Mater. 2014, 197, 194-203.

(34) Ho, T. A.; Criscenti, L. J.; Wang, Y. Nanostructural Control of Methane Release in Kerogen and Its Implications to Wellbore Production Decline. Sci. Rep. 2016, 6, 28053.

(35) Collell, J.; Galliero, G.; Vermorel, R.; Ungerer, P.; Yiannourakou, M.; Montel, F.; Pujol, M. Transport of Multicomponent Hydrocarbon Mixtures in Shale Organic Matter by Molecular Simulations. J Phys Chem C 2015, 119, 22587-22595.

(36) Falk, K.; Coasne, B.; Pellenq, R.; Ulm, F.-J.; Bocquet, L. Subcontinuum Mass Transport of Condensed Hydrocarbons in Nanoporous Media. Nat. Commun. 2015, 6, 6949.

(37) Obliger, A.; Pellenq, R.; Ulm, F.-J.; Coasne, B. Free Volume Theory of Hydrocarbon Mixture Transport in Nanoporous Materials. J. Phys. Chem. Lett. 2016, 7, 3712-3717. 
(38) Vasileiadis, M.; Peristeras, L. D.; Papavasileiou, K. D.; Economou, I. G. Modeling of Bulk Kerogen Porosity: Methods for Control and Characterization. Energy Fuels 2017, 31, 6004-6018.

(39) Wang, J.; Wolf, R. M.; Caldwell, J. W.; Kollman, P. A.; Case, D. A. Development and Testing of a General Amber Force Field. J Comput Chem 2004, 25, 1157-1174.

(40) Bayly, C. I.; Cieplak, P.; Cornell, W.; Kollman, P. A. A Well-Behaved Electrostatic Potential Based Method Using Charge Restraints for Deriving Atomic Charges: The RESP Model. J. Phys. Chem. 1993, 97, 10269-10280.

(41) Ehlinger, V. M.; Gabriel, K. J.; Noureldin, M. M. B.; El-Halwagi, M. M. Process Design and Integration of Shale Gas to Methanol. ACS Sustain. Chem. Eng. 2014, 2, 30-37.

(42) Karnkowski, P. H.; Pikulski, L.; Wolnowski, T. Petroleum Geology of the Polish Part of the Baltic Region - an Overview. Geol. Q. 2010, 54, 143-158.

(43) Martin, M. G.; Siepmann, J. I. Transferable Potentials for Phase Equilibria. 1. UnitedAtom Description of N-Alkanes. J. Phys. Chem. B 1998, 102, 2569-2577.

(44) Potoff, J. J.; Siepmann, J. I. Vapor-liquid Equilibria of Mixtures Containing Alkanes, Carbon Dioxide, and Nitrogen. AIChE J. 2001, 47, 1676-1682.

(45) Yang, Q.; Zhong, C. Molecular Simulation of Carbon Dioxide/Methane/Hydrogen Mixture Adsorption in Metal-Organic Frameworks. J. Phys. Chem. B 2006, 110, 1777617783.

(46) Babarao, R.; Hu, Z.; Jiang, J.; Chempath, S.; Sandler, S. I. Storage and Separation of $\mathrm{CO}_{2}$ and $\mathrm{CH}_{4}$ in Silicalite, $\mathrm{C}_{168}$ Schwarzite, and IRMOF-1: A Comparative Study from Monte Carlo Simulation. Langmuir 2007, 23, 659-666. 
(47) Shah, J. K.; Maginn, E. J. Monte Carlo Simulations of Gas Solubility in the Ionic Liquid 1- N -Butyl-3-Methylimidazolium Hexafluorophosphate. J. Phys. Chem. B 2005, 109, 1039510405

(48) Jakobtorweihen, S.; Verbeek, M. G.; Lowe, C. P.; Keil, F. J.; Smit, B. Understanding the Loading Dependence of Self-Diffusion in Carbon Nanotubes. Phys. Rev. Lett. 2005, 95, 44501/1-44501/4.

(49) Aimoli, C. G.; Maginn, E. J.; Abreu, C. R. A. Force Field Comparison and Thermodynamic Property Calculation of Supercritical CO2 and CH4 Using Molecular Dynamics Simulations. Fluid Phase Equilibria 2014, 368, 80-90.

(50) Nath, S. K.; Escobedo, F. A.; de Pablo, J. J. On the Simulation of Vapor-liquid Equilibria for Alkanes. J. Chem. Phys. 1998, 108, 9905-9911.

(51) Frenkel, D.; Smit, B. Understanding Molecular Simulation: From Algorithms to Applications, 2nd ed.; Computational science series; Academic Press: San Diego, 2002.

(52) Shah, J. K.; Marin-Rimoldi, E.; Mullen, R. G.; Keene, B. P.; Khan, S.; Paluch, A. S.; Rai, N.; Romanielo, L. L.; Rosch, T. W.; Yoo, B.; et al. Cassandra: An Open Source Monte Carlo Package for Molecular Simulation. J. Comput. Chem. 2017, 38, 1727-1739.

(53) Ramos, J.; Peristeras, L. D.; Theodorou, D. N. Monte Carlo Simulation of Short Chain Branched Polyolefins in the Molten State. Macromolecules 2007, 40, 9640-9650.

\begin{tabular}{lllll|l} 
(54) MAPS platform. Current version is 4.0 & Scienomics
\end{tabular} http://www.scienomics.com/products/molecular-modeling-platform (accessed Sep 22, 2016).

(55) Plimpton, S. Fast Parallel Algorithms for Short-Range Molecular Dynamics. J. Comput. Phys. 1995, 117, 1-19. 
(56) Martin, M. G. MCCCS Towhee: A Tool for Monte Carlo Molecular Simulation. Mol. Simul. 2013, 39, 1212-1222.

(57) McDonald, I. R. NpT -Ensemble Monte Carlo Calculations for Binary Liquid Mixtures. Mol. Phys. 1972, 23, 41-58.

(58) Widom, B. Some Topics in the Theory of Fluids. J. Chem. Phys. 1963, 39, 2808-2812.

(59) Hoover, W. G. Canonical Dynamics: Equilibrium Phase-Space Distributions. Phys Rev A 1985, 31, 1695-1697.

(60) Shinoda, W.; Shiga, M.; Mikami, M. Rapid Estimation of Elastic Constants by Molecular Dynamics Simulation under Constant Stress. Phys. Rev. B 2004, 69.

(61) Berendsen, H. J. C.; van der Spoel, D.; van Drunen, R. GROMACS: A MessagePassing Parallel Molecular Dynamics Implementation. Comput. Phys. Commun. 1995, 91, 4356.

(62) Van Der Spoel, D.; Lindahl, E.; Hess, B.; Groenhof, G.; Mark, A. E.; Berendsen, H. J. C. GROMACS: Fast, Flexible, and Free. J. Comput. Chem. 2005, 26, 1701-1718.

(63) Pronk, S.; Páll, S.; Schulz, R.; Larsson, P.; Bjelkmar, P.; Apostolov, R.; Shirts, M. R.; Smith, J. C.; Kasson, P. M.; van der Spoel, D.; et al. GROMACS 4.5: A High-Throughput and Highly Parallel Open Source Molecular Simulation Toolkit. Bioinformatics 2013, 29, 845-854.

(64) Mosher, K.; He, J.; Liu, Y.; Rupp, E.; Wilcox, J. Molecular Simulation of Methane Adsorption in Micro- and Mesoporous Carbons with Applications to Coal and Gas Shale Systems. Int. J. Coal Geol. 2013, 109-110, 36-44. 


\section{Tables}

Table 1. The pressure (atm) in which adsorption was studied using GCMC for the pure and mixed gases of interest in this work.

\begin{tabular}{|c|c|c|c|c|}
\hline $\mathrm{CH}_{4}$ & $\mathrm{C}_{2} \mathrm{H}_{6}$ & $n-\mathrm{C}_{4} \mathrm{H}_{10}$ & $\mathrm{CO}_{2}$ & $\begin{array}{c}\text { Shale gas } \\
\text { mixture }\end{array}$ \\
\hline $\begin{array}{c}1 \\
20 \\
50 \\
100 \\
250\end{array}$ & $\begin{array}{c}0.5 \\
1 \\
5 \\
10 \\
15 \\
100 \\
250\end{array}$ & $\begin{array}{c}0.1 \\
0.25 \\
0.5 \\
0.75 \\
1 \\
100 \\
250\end{array}$ & $\begin{array}{c}1 \\
100 \\
250\end{array}$ & $\begin{array}{c}1 \\
250\end{array}$ \\
\hline
\end{tabular}


Table 2. Correlation coefficient between maximum component of diffusion coefficient and four major characteristics of porosity (LPD, MPD, $\mathrm{CH}_{4}$ accessible volume $V_{\text {acc }}$, and $\mathrm{CH}_{4}$ accessible surface $S_{\text {acc }}$ ) for the four temperature and pressure conditions considered.

\begin{tabular}{|c|c|c|c|c|c|c|c|c|}
\hline $298.15 \mathrm{~K}$ & \multicolumn{4}{|c|}{$1 \mathrm{~atm}$} & \multicolumn{4}{|c|}{$250 \mathrm{~atm}$} \\
\hline & LPD & MPD & $V_{\text {acc }}$ & $S_{\text {acc }}$ & LPD & MPD & $V_{\text {acc }}$ & $S_{\text {acc }}$ \\
\hline $\mathrm{CH}_{4}$ & 0.847 & 0.313 & 0.784 & 0.743 & 0.919 & 0.438 & 0.727 & 0.660 \\
\hline $\mathrm{C}_{2} \mathrm{H}_{6}$ & 0.935 & 0.424 & 0.779 & 0.773 & 0.850 & 0.290 & 0.630 & 0.598 \\
\hline $\mathrm{CO}_{2}$ & 0.877 & 0.450 & 0.791 & 0.753 & 0.896 & 0.412 & 0.646 & 0.655 \\
\hline $\begin{array}{c}\mathrm{CH}_{4} \\
\text { in mixture }\end{array}$ & & & & & 0.946 & 0.407 & 0.724 & 0.654 \\
\hline $\begin{array}{c}\mathrm{C}_{2} \mathrm{H}_{6} \\
\text { in mixture }\end{array}$ & & & & & 0.975 & 0.394 & 0.697 & 0.626 \\
\hline $\begin{array}{c}\mathrm{CO}_{2} \\
\text { in mixture }\end{array}$ & & & & & 0.885 & 0.479 & 0.812 & 0.725 \\
\hline $398.15 \mathrm{~K}$ & & & & & & & & \\
\hline $\mathrm{CH}_{4}$ & 0.904 & 0.408 & 0.738 & 0.747 & 0.950 & 0.419 & 0.732 & 0.661 \\
\hline $\mathrm{C}_{2} \mathrm{H}_{6}$ & 0.870 & 0.527 & 0.794 & 0.684 & 0.901 & 0.303 & 0.678 & 0.620 \\
\hline $\mathrm{CO}_{2}$ & 0.757 & 0.316 & 0.676 & 0.741 & 0.955 & 0.489 & 0.749 & 0.638 \\
\hline $\begin{array}{c}\mathrm{CH}_{4} \\
\text { in mixture }\end{array}$ & & & & & 0.962 & 0.365 & 0.678 & 0.594 \\
\hline $\begin{array}{c}\mathrm{C}_{2} \mathrm{H}_{6} \\
\text { in mixture }\end{array}$ & & & & & 0.961 & 0.342 & 0.616 & 0.548 \\
\hline $\begin{array}{c}\quad \mathrm{CO}_{2} \\
\text { in mixture }\end{array}$ & & & & & 0.925 & 0.426 & 0.690 & 0.566 \\
\hline
\end{tabular}




\section{Figures}

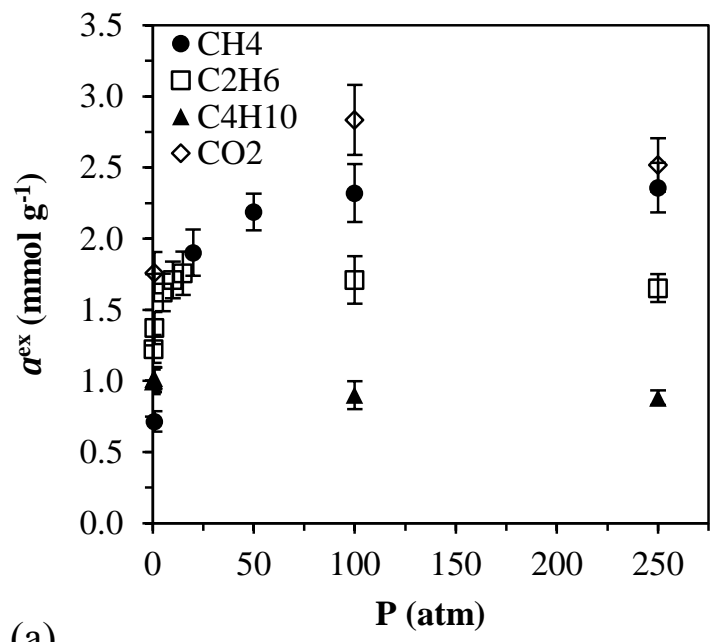

(a)

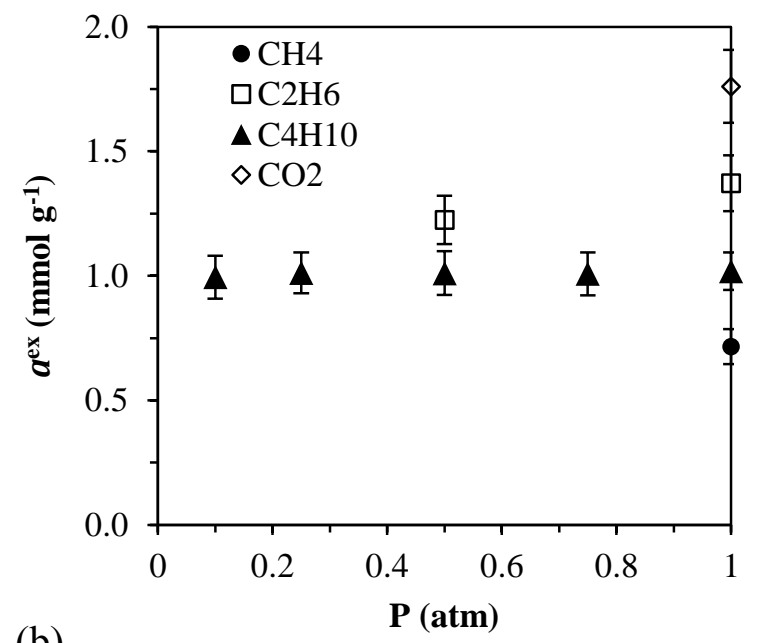

(b)

Figure 1. Excess adsorption isotherms of $\mathrm{CH}_{4}, \mathrm{C}_{2} \mathrm{H}_{6}, n-\mathrm{C}_{4} \mathrm{H}_{10}$ and $\mathrm{CO}_{2}$ at $298.15 \mathrm{~K}$ to kerogen constructed without the aid of LJ dummy particles, (a) the whole scale from 0 atm to $250 \mathrm{~atm}$ is presented, (b) the pressure region up to $1 \mathrm{~atm}$ is presented. 


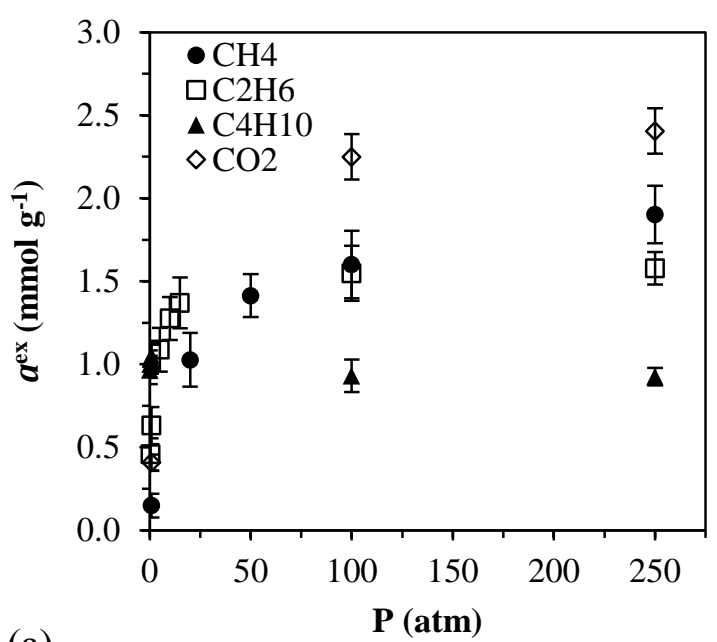

(a)

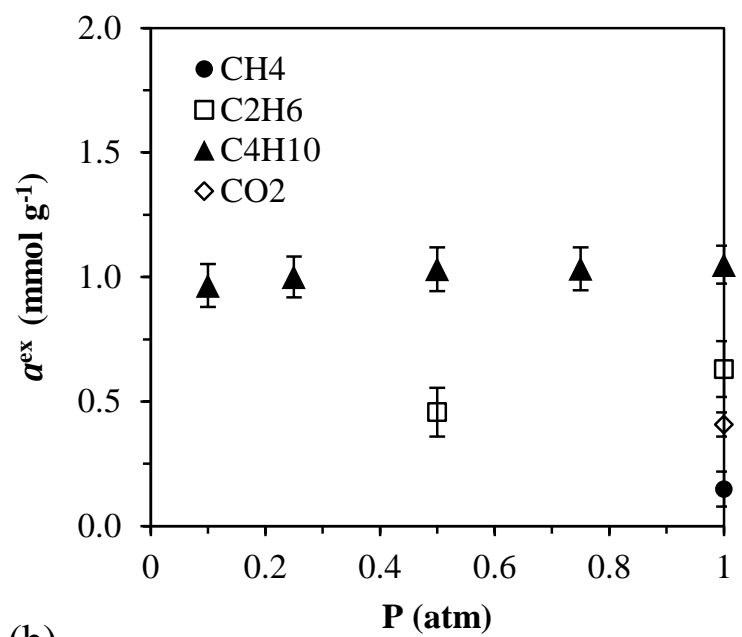

(b)

Figure 2. Excess adsorption isotherms of $\mathrm{CH}_{4}, \mathrm{C}_{2} \mathrm{H}_{6}, \mathrm{C}_{4} \mathrm{H}_{10}$ and $\mathrm{CO}_{2}$ at $398.15 \mathrm{~K}$ to kerogen constructed without the aid of LJ dummy particles, (a) the whole scale from 0 atm to $250 \mathrm{~atm}$ is presented, (b) the pressure region up to $1 \mathrm{~atm}$ is presented. 

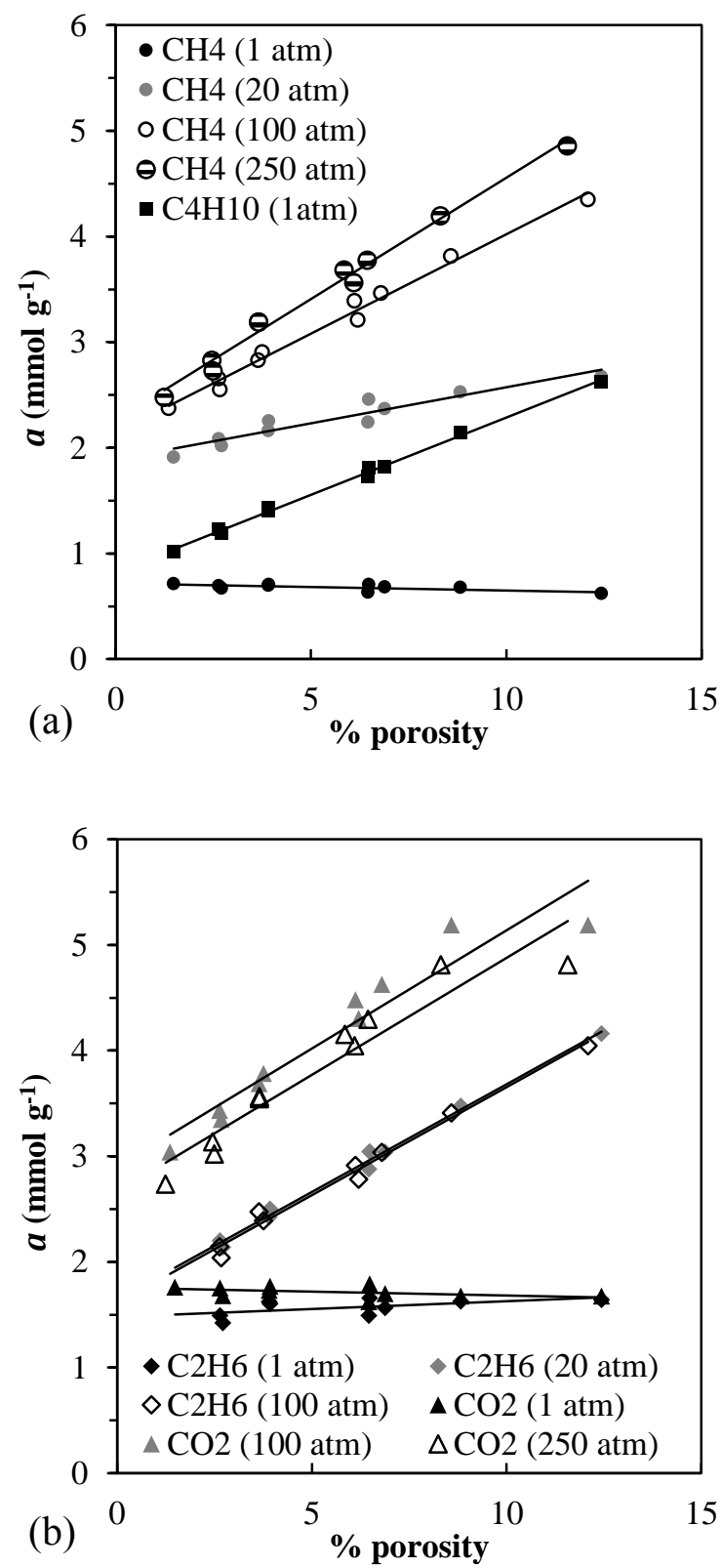

Figure 3. Adsorbed amount of (a) $\mathrm{CH}_{4}, \mathrm{C}_{4} \mathrm{H}_{10}$ and (b) $\mathrm{C}_{2} \mathrm{H}_{6}, \mathrm{CO}_{2}$ on kerogen as function of \% porosity of kerogen. 


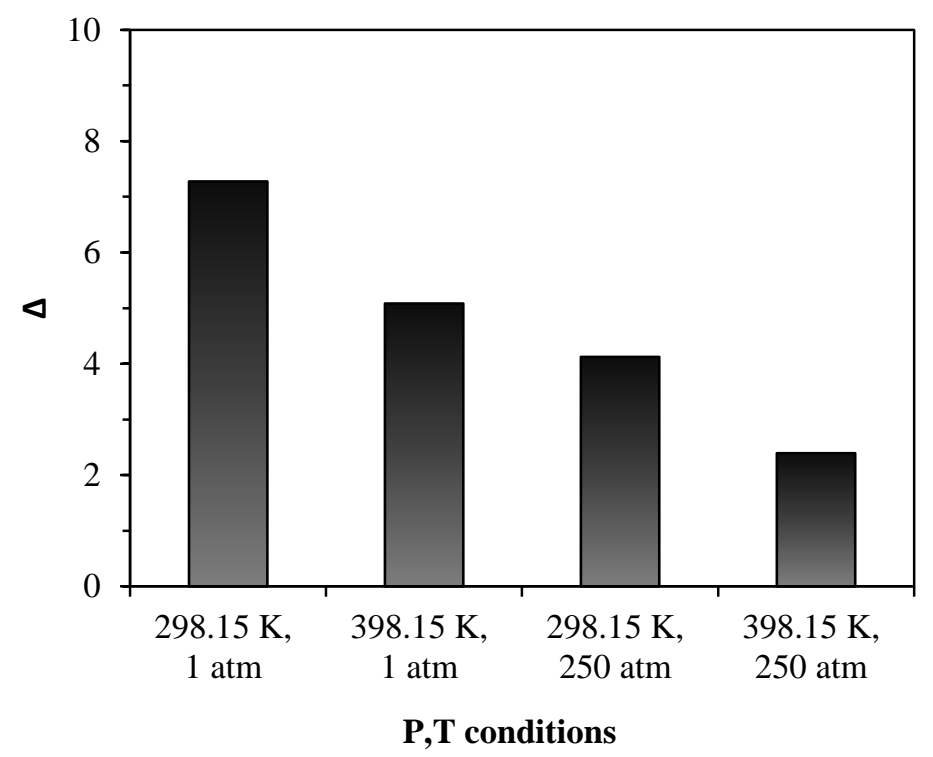

Figure 4. Quantity $\Delta$ for the shale mixture under confinement in kerogen as function of the four pressure and temperature conditions considered. 


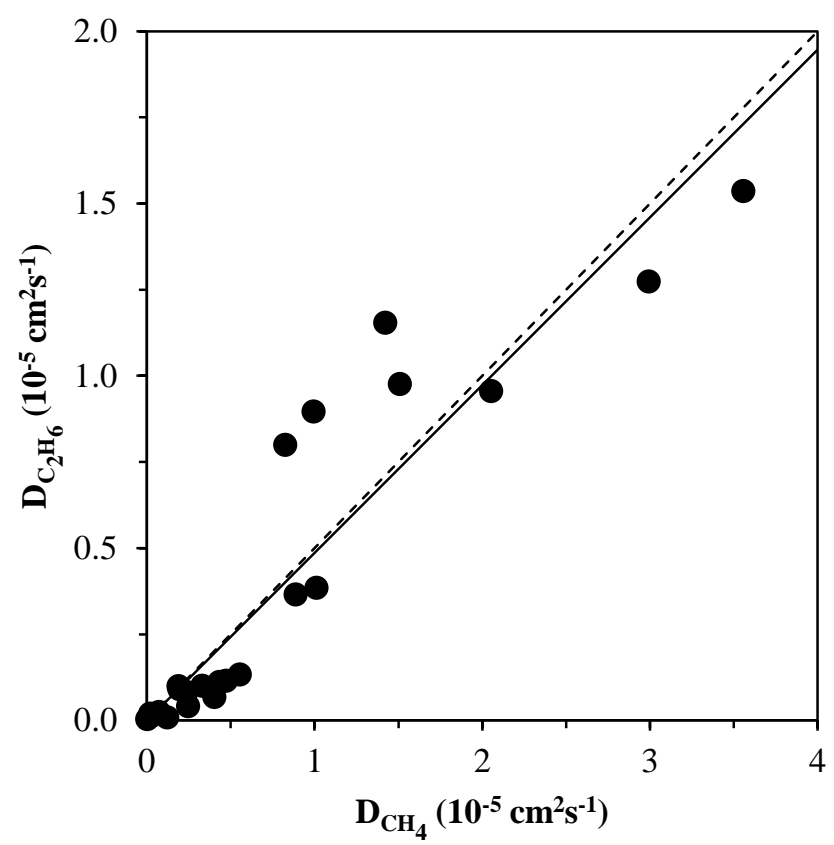

Figure 5. Diffusion coefficient of $\mathrm{C}_{2} \mathrm{H}_{6}$ against the diffusion coefficient of $\mathrm{CH}_{4}$ along the different structures considered at $298.15 \mathrm{~K}$ and $1 \mathrm{~atm}$. The dashed line corresponds to $y=0.5 x$ while the continuous line is a linear trend line fitted to the data, with a slope of 0.4865 . 


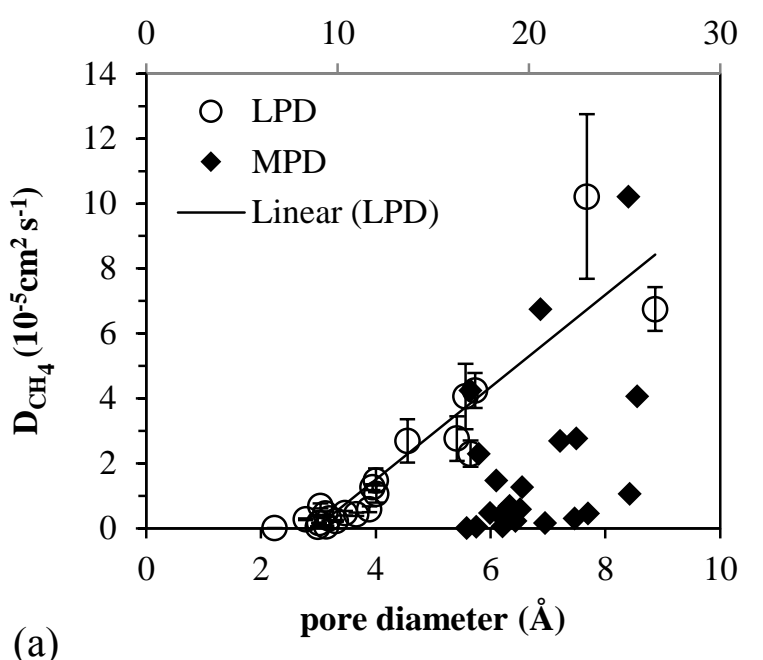

(a)
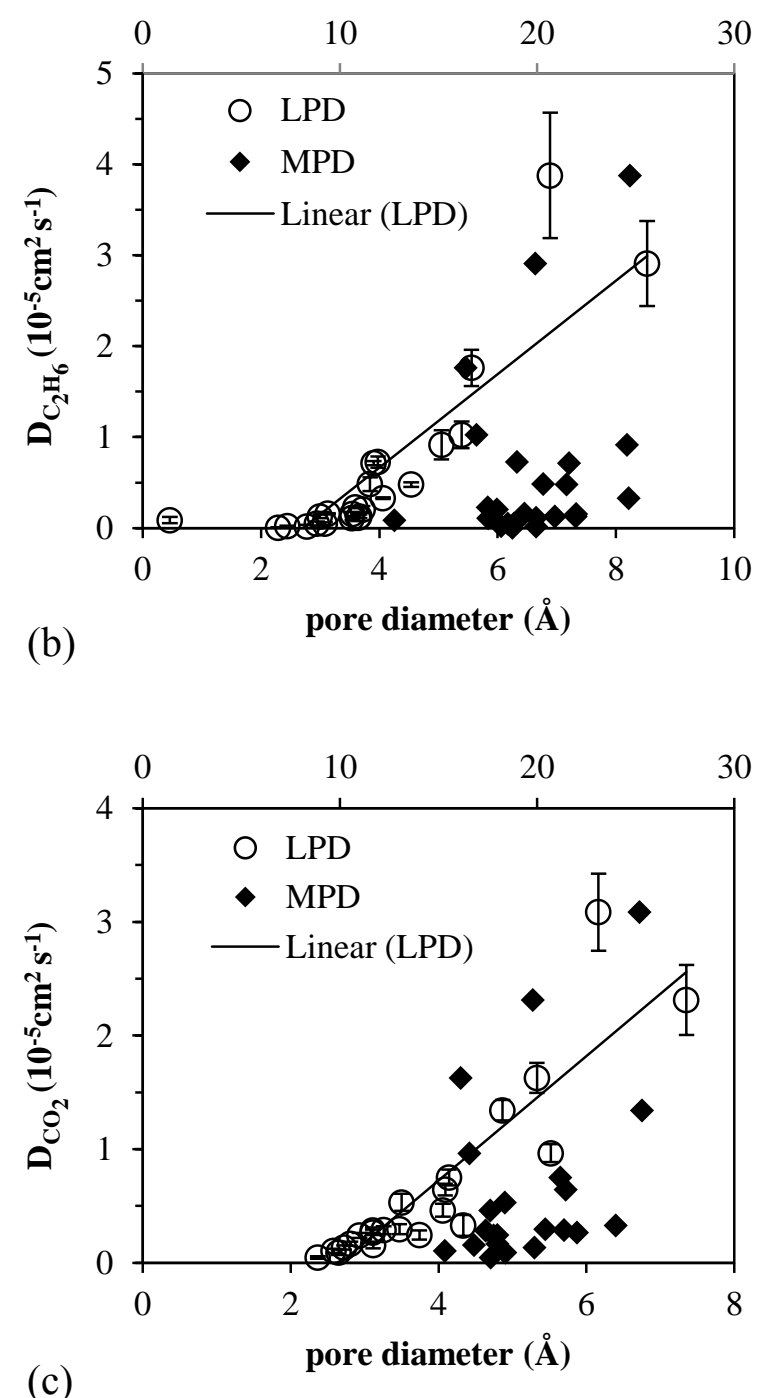

Figure 6. Maximum component of (a) $\mathrm{CH}_{4}$, (b) $\mathrm{C}_{2} \mathrm{H}_{6}$ and (c) $\mathrm{CO}_{2}$ diffusion coefficient (along kerogen) at $298.15 \mathrm{~K}$ and $250 \mathrm{~atm}$ as a function of the LPD (shown on the primary horizontal 
axis) and MPD (shown on the secondary horizontal axis). A linear trend line is fitted to the D vs LPD points. The statistical uncertainty for the D vs MPD points is the same as for the D vs LPD points. 


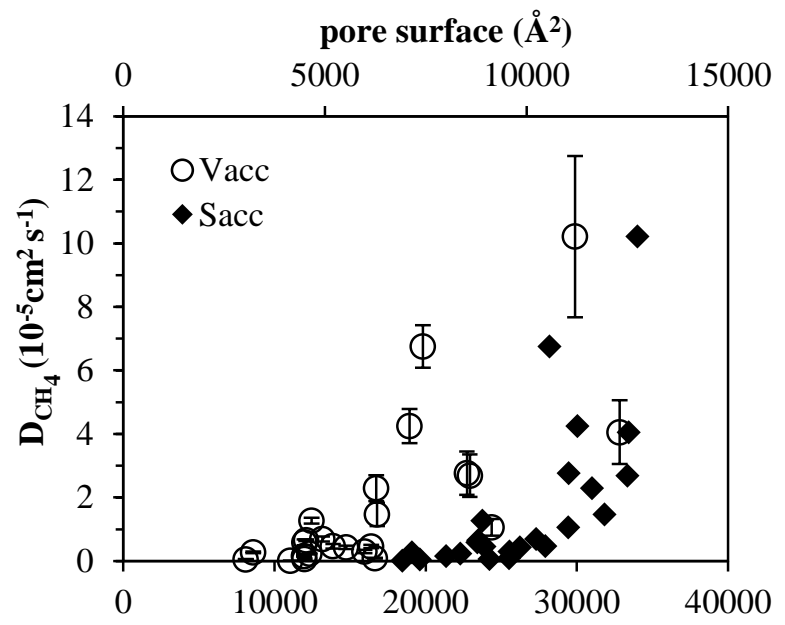

(a)

pore volume $\left(\AA^{3}\right)$

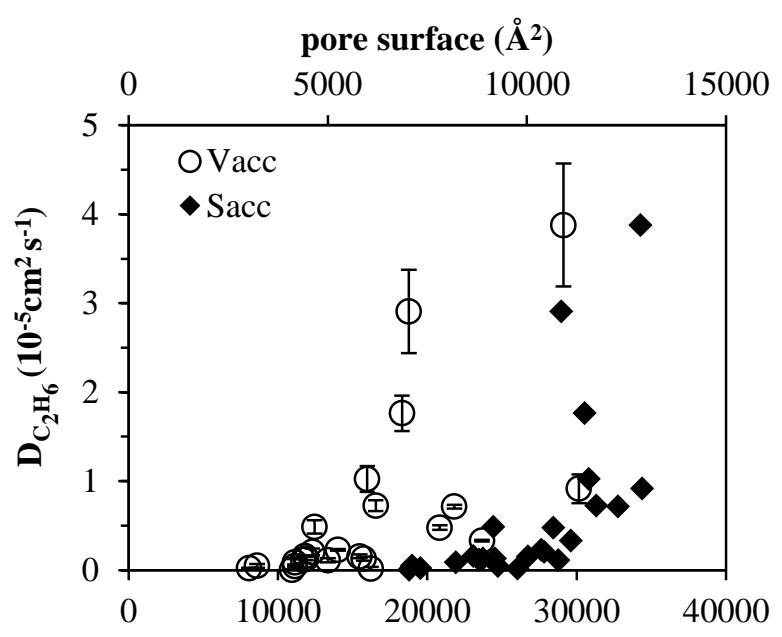

(b)

pore volume $\left(\AA^{3}\right)$

pore surface $\left(\AA^{2}\right)$

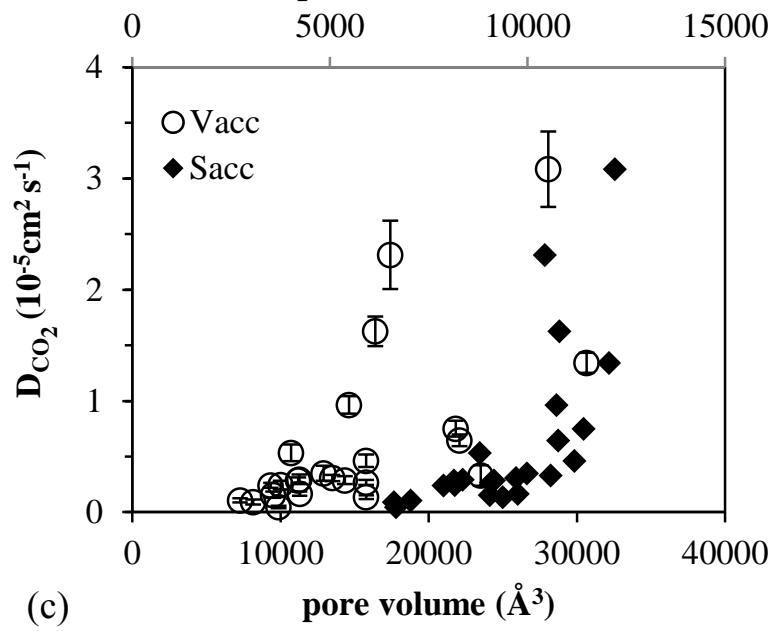

Figure 7. Maximum component of (a) $\mathrm{CH}_{4}$, (b) $\mathrm{C}_{2} \mathrm{H}_{6}$ and (c) $\mathrm{CO}_{2}$ diffusion coefficient (along kerogen) at $298.15 \mathrm{~K}$ and $250 \mathrm{~atm}$ as a function of the $\mathrm{CH}_{4}$ accessible volume, $V_{\text {acc}}$, (shown on the primary horizontal axis) and $\mathrm{CH}_{4}$ accessible surface, $V_{\text {acc}}$, (shown on the secondary 
horizontal axis) or kerogen. The statistical uncertainty for the D vs $S_{\text {acc }}$ points is the same as for the D vs $V_{\text {acc }}$ points. 

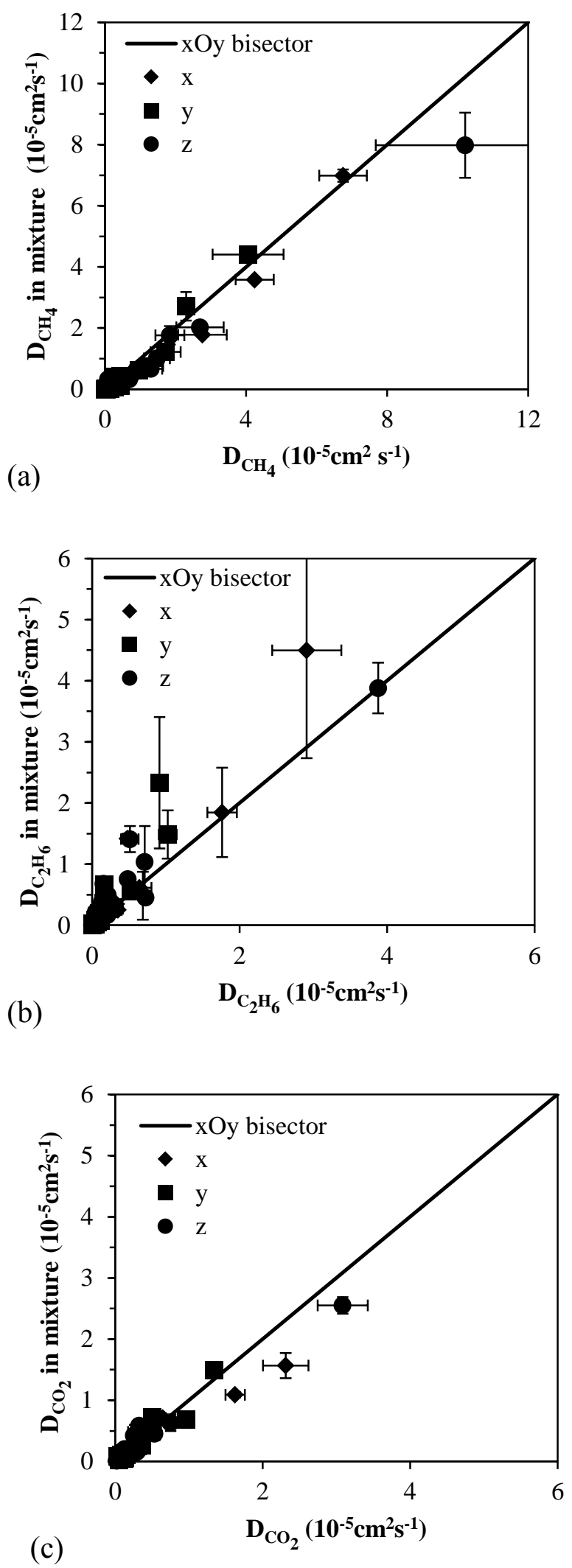

Figure 8. (a) $\mathrm{CH}_{4}$, (b) $\mathrm{C}_{2} \mathrm{H}_{6}$ and (c) $\mathrm{CO}_{2}$ diffusion coefficient(along kerogen) components $\mathrm{x}$ (diamonds), y (squares) and z (circles) in SG mixture versus the corresponding components of 
pure compounds for the different kerogen structures at $298.15 \mathrm{~K}$ and $250 \mathrm{~atm}$. Black line is the bisector of the angle defined by the vertical and horizontal axes.

\section{Table of contents graphic}

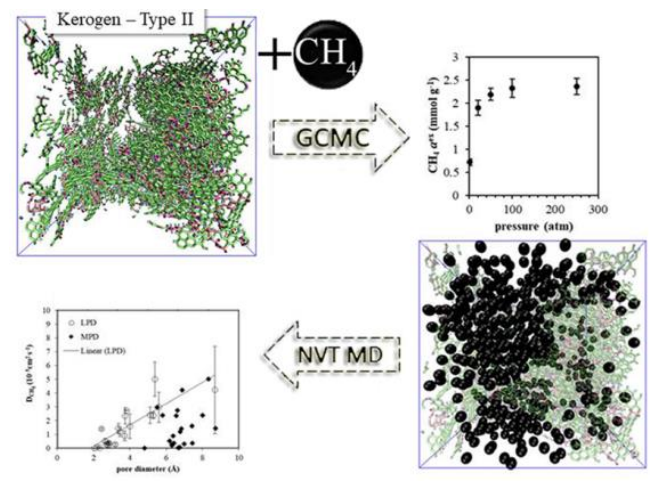

